\title{
Experimental Evaluation of the VBCM Model for Nucleophilic Substitutions
}

\author{
Torben Lund and Henning Lund
}

Department of Organic Chemistry, University of Aarhus, DK-8000 Århus C, Denmark

\begin{abstract}
Lund, T. and Lund, H., 1988. Experimental Evaluation of the VBCM Model for Nucleophilic Substitutions. - Acta Chem Scand., Ser. B 42: 269-279.

The rate of the substitution reaction, $k_{\mathrm{SUB}}$, between different conjugated nucleophiles (enolates, dianions and neutral nucleophiles) and alkyl and benzyl halides has been measured by cyclic voltammetry. The SET vs. $\mathrm{S}_{\mathrm{N}} 2$ character of the transition state (TS) was evaluated from the value of $k_{\text {SUB }}$ relative to the outersphere electron transfer rate, $k_{\mathrm{SET}}$, obtained for the reaction between an anion radical $\left(\mathrm{A}^{-}\right)$with the same oxidation potential as the nucleophile and the alkyl halide in question. For different alkyl and benzyl halides $k_{\mathrm{SUB}} / k_{\mathrm{SET}}$ ratios in the range 1-4000 were obtained, which was interpreted as indicating the possibility of transition states between a pure SET TS and a pure $S_{N} 2$ TS rather than competition between SET and $\mathrm{S}_{\mathrm{N}} 2$. The observed changes in $k_{\mathrm{SUB}}$ and $k_{\mathrm{SUB}} / k_{\mathrm{SET}}$ as a function of the choice of nucleophile $(\mathrm{Nu})$, alkyl group $(\mathrm{R})$ and leaving group $(\mathrm{X})$ were compared with the changes predicted by the valence bond configuration mixing model (VBCM). It was concluded that the VBCM model has reasonably good predictive power in the region of the continuous TS model which is SETlike.
\end{abstract}

Since the middle of the nineteen thirties the mechanism of the nucleophile substitution reaction has been described as a polar two-electron mechanism in which the nucleophile transfers two electrons to the new bond which is established to the electrophilic center. The mechanism is described by the well-known curved arrows. ${ }^{1,2}$ In the frontier orbital model developed 25-30 years later the $\mathrm{S}_{\mathrm{N}} 2$ model is also described as a polar two-electron mechanism in which two electrons in a non-bonding $p$ orbital on the nucleophile are transferred to the new bond. ${ }^{3}$ However, during the last 20 years an increasing number of nucleophilic reactions have been proposed to proceed through an initial transfer of one electron. ${ }^{4-15}$ Single electron transfer (SET) has also been postulated in organometallic reactions, ${ }^{16,17}$ electrophilic substitution processes, ${ }^{18}$ and in the $\mathrm{S}_{\mathrm{RN}} 1$ reaction. ${ }^{19,20}$ In most investigations the $\mathrm{S}_{\mathrm{N}} 2$ and the SET mechanisms have been stated ${ }^{13,16}$ or tacitly assumed to be two independent and competing mechanisms.

Shaik and Pross have proposed ${ }^{21-24}$ a valence bond configuration mixing model (VCBM) ac- cording to which all nucleophilic reactions proceed through an initial shift of one electron:

$\mathrm{Nu}:^{-}+\mathrm{R}-\mathrm{X} \rightarrow$

$\left[\mathrm{Nu}:^{-} \mathrm{R}^{*} \mathrm{X} \leftrightarrow \mathrm{Nu} \cdot \cdot \mathrm{R}: \mathrm{X}^{-}\right]^{\neq} \rightarrow \mathrm{Nu}-\mathrm{R}+\mathrm{X}^{-}$

If the interaction between $\mathrm{Nu}^{\prime}$ and $\mathrm{R}$ in the transition state (TS) is zero or very weak, the mechanism can be classified as an outer-sphere SET mechanism. In this case there will be a possibility for the radicals $\mathrm{Nu}^{\circ}$ and $\mathrm{R}^{\cdot}$ to escape from the solvent cage. If the bonding between $\mathrm{Nu}^{\circ}$ and $\mathbf{R}^{\cdot}$ is strong then the coupling is synchronous with the electron shift, and the TS will be equivalent to the classical $\mathrm{S}_{\mathrm{N}} 2$ transition state.

The formation of the activation barrier is explained by an avoided crossing between a donoracceptor configuration DA and a charge transfer configuration $\mathrm{D}^{+} \mathrm{A}^{-}$(Fig. 1). ${ }^{25}$

The activation energy, $\Delta E$, is a fraction, $f$, of the difference between the ionization potential of the nucleophile $\left(I_{\mathrm{Nu}}\right)$ and the electron affinity of the substrate $\left(A_{\mathrm{RX}}\right)$ : 


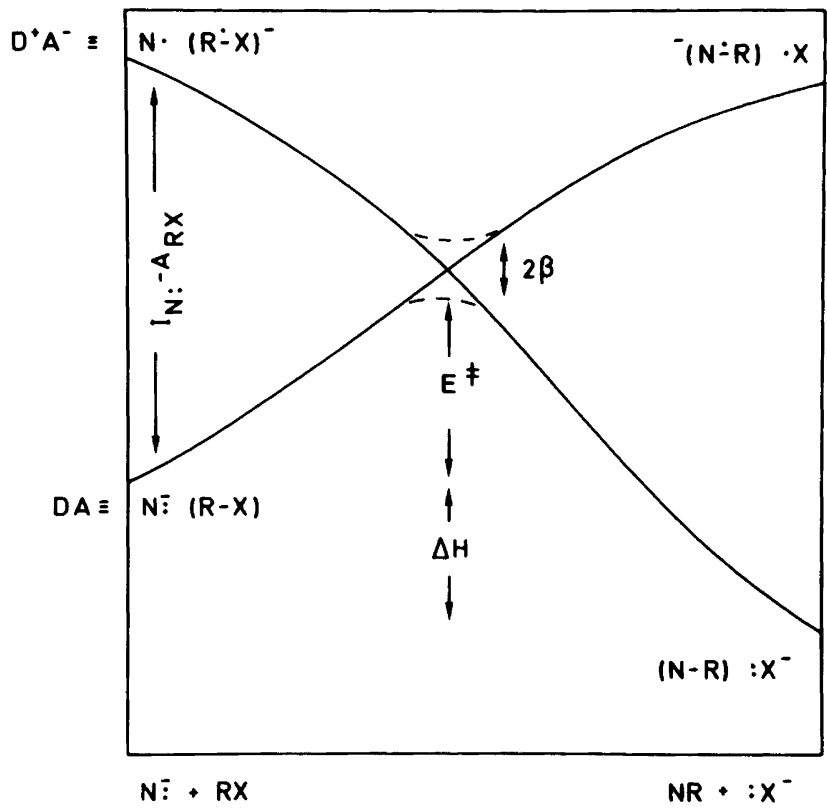

Fig. 1. State correlation diagram for an $\mathrm{S}_{\mathrm{N}} 2$ reaction. The lower states are ground states of reactants and products, while the upper states are the corresponding charge transfer states. $\beta$ is the degree of avoided crossing. $\Delta E^{*}$ is the reaction barrier (from Ref. 21).

$$
\Delta E=f\left(I_{\mathrm{Nu}}-A_{\mathrm{RX}}\right)-\beta
$$

$2 \beta$ is the electronic energy of interaction between the DA and $\mathrm{D}^{+} \mathrm{A}^{-}$configuration in the TS. tions:

This simple model gives the following predic-

A. If the steric hindrance of $R$ is increased, the SET character of the TS will increase.

B. SET and $\mathrm{S}_{\mathrm{N}} 2$ are the two extremes of the same underlying mechanism with a continuous transition between these.

C. If the electron-donating power of the nucleophile is increased $\left(I_{\mathrm{Nu}}\right.$ decreased) or the electron-accepting ability of the substrate is increased ( $A_{\mathrm{RX}}$ increased), then the activation energy will decrease [cf. eqn. (1)].
D. The TS for a good electron donor will be located earlier on the reaction coordinate than that for a poor donor (see Fig. 2). The electron shift will therefore take place earlier during the reaction and in a molecular geometry which is more reactant-like. This is illustrated in the simple diagram of Scheme 1.

The distance between $\mathrm{Nu}$ and $\mathrm{R}$ in the TS is longer for the good donor than for the poor donor and steric hindrance thus plays a smaller role. In general, the interaction between DA and $\mathrm{D}^{+} \mathrm{A}^{-}$in the TS is decreased as the distance in the TS between $\mathrm{Nu}^{\prime}$ and $\mathrm{R}$ is increased. In the following we will interpret this interaction very simply as the bonding interaction between $\mathrm{Nu}^{\circ}$
Good Donor:<smiles>[N+]=[N+]=[W]</smiles>

Poor Donor:
SET-TS:

'R : $\mathbf{X}^{-}$

$S_{N} 2-T S:$

$$
\mathrm{Nu}^{-} \mathbf{R}^{\cdot} \mathrm{X} \rightarrow \mathrm{Nu} \mathbf{\prime}^{\prime} \mathrm{R}^{\prime} \mathbf{X}^{-}
$$

Scheme 1. 


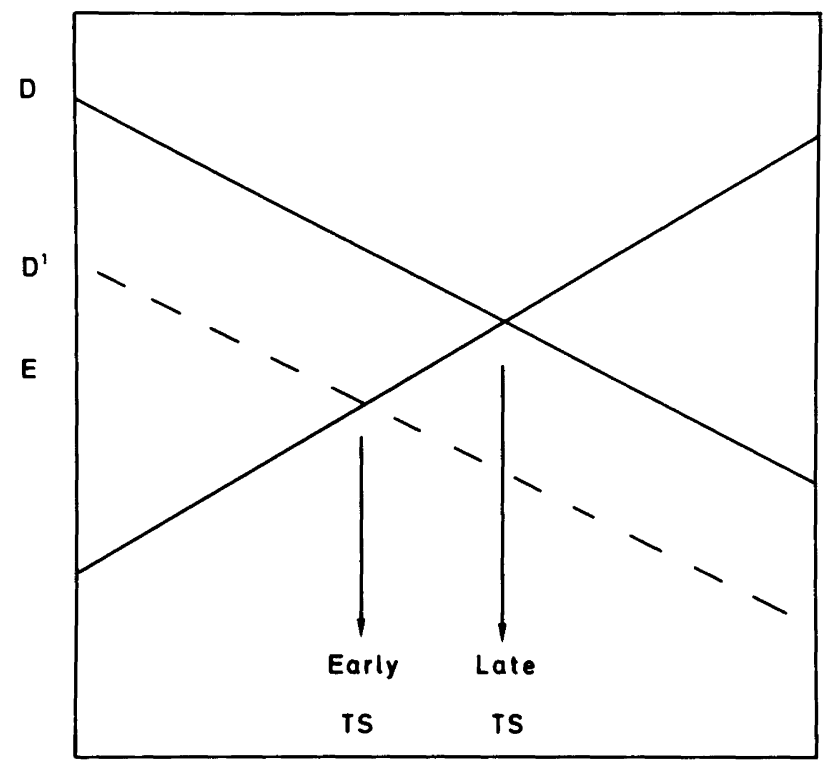

Fig. 2. The effect of changing the donor $D$ to a better donor $D^{\prime}$. The TS is located earlier on the reaction coordinate for the good donor than for the poor donor (from Ref. 21).

Reaction Coordinate

and $R$. The bond energy in the TS will therefore be smallest for the good donor and the TS will thus be more SET-like.

Recently we have been able by a kinetic procedure ${ }^{26-28}$ to establish the plausibility that the ratedetermining step in the aliphatic nucleophilic reaction of the enolate anion 1,4-dihydro-4-methoxycarbonyl-1-methylpyridine $\left(\mathbf{1}^{-}\right)$with a number of sterically hindered alkyl bromides, ${ }^{26}$ benzyl chlorides ${ }^{27}$ and vicinal dihalides ${ }^{28}$ was the transfer of a single electron. In order to test the Shaik and Pross predictions A, B, C and D listed above and to obtain more information about the parameters determining the size of the nucleophilic activation barrier, a number of nucleophiles with different redox potential have been included in this investigation. The nucleophiles $\mathbf{1}^{-}, \mathbf{1}^{\prime-}, \mathbf{2}^{-}, \mathbf{P e}^{2-}$, $\mathbf{A Q}^{2-}, \mathbf{B V}$ and $\mathbf{M V}$ are generated electrochemically in two one-electron reductions from 4-methoxycarbonyl-1-methylpyridinium iodide $\left(1^{+}\right)$, 4-benzoyl-1-methylpyridinium iodide $\left(1^{\prime+}\right)$, 2,4,6-triphenylthiopyrylium perchlorate $\left(2^{+}\right)$, perylene (Pe), anthraquinone (AQ), 1,1'-dibenzyl-4,4'-bipyridinium diperchlorate $\left(\mathbf{B V}^{2+}\right)$, and 1,1'-dimethyl-4,4'-bipyridinium diperchlorate $\left(\mathbf{M V}^{2+}\right)$, respectively. The nucleophiles (Scheme<smiles>[R]C(=O)c1cc[n+](C)cc1</smiles>

$1^{+}: \mathrm{R}=\mathrm{OCH}_{3}$

$1^{\prime+}: R=\mathrm{C}_{6} \mathrm{H}_{5}$<smiles></smiles>

$\mathbf{2}^{+}$<smiles>[R][n+]1ccc(-c2cc[n+]([R])cc2)cc1</smiles>

$$
\begin{aligned}
& \mathbf{B V}^{2+}: \mathbf{R}=\mathrm{C}_{6} \mathrm{H}_{5} \mathrm{CH}_{2} \\
& \mathbf{M V}^{2+}: \mathbf{R}=\mathrm{CH}_{3} \\
& \text { HV }^{2+}: \mathbf{R}=\mathbf{H}
\end{aligned}
$$

\section{Scheme 2.}


2) thus represent neutral species (BV and MV) and compounds bearing one $\left(1^{-}, 1^{\prime-}\right.$ and $\left.2^{-}\right)$or two $\left(\mathbf{P e}^{2-} \cdot \mathbf{A Q}^{2-}\right)$ negative charges.

\section{Results}

The basic assumption for our kinetic arguments is that anion radicals of aromatic compounds react with aliphatic halides through the initial transfer of an electron. If the redox potentials of A [eqn. (2)] and $\mathrm{Nu}^{-}$[eqn. (3)] are equal, and the total solvent and bond reorganization energies, $\lambda$, of eqns. (2) and (3) also are equal, then the result $k_{\mathrm{SET}}=k_{\mathrm{SUB}}$ is taken as an indication of an electron-transfer being the rate-determining step in the nucleophilic substitution. ${ }^{26-28} \mathrm{~A}$ small difference between $\lambda_{A}(0)$ and $\lambda_{N u}(0)$ is of minor importance as $\lambda_{\mathrm{RX}}(0)$ is approximately 10 times larger than $\lambda_{A}(0)$.

$\mathrm{A}^{\cdot-}+\mathrm{RX} \stackrel{k_{\mathrm{SET}}}{\longrightarrow} \mathrm{A}+\mathrm{R}^{\cdot}+\mathrm{X}^{-}$

$\mathrm{Nu}^{-}+\mathrm{RX} \stackrel{k_{\text {SUB }}}{\longrightarrow} \mathrm{Nu}^{\cdot}+\cdot \mathrm{R}+\mathrm{X}^{-}$

The general cases of the SET and polar pathways are illustrated in Fig. 3.

Usually the activation barrier $\Delta E^{\neq}$for the polar reaction will be lower than for the SET reaction $\left(k_{\mathrm{SUB}}>k_{\mathrm{SET}}\right)$ due to bond formation in the TS between $\mathrm{Nu}$ ' and ' $\mathrm{R}$ which stabilizes the TS and decreases the activation energy. If we assume that the energy associated with change of the entropy of activation, $T \Delta \Delta S^{\ddagger}$, on going from the polar to the SET reaction is small compared to the change in the enthalpy of activation, $\Delta \Delta H^{\ddagger}$, the stabilization energy in the TS can be related to the change in the free energy of activation $\Delta \Delta G^{\neq}$according to:

$\Delta \Delta G^{*} \simeq=-2.3 R T \log \left(k_{\mathrm{SUB}} / k_{\mathrm{SET}}\right)$

where $k_{\mathrm{SET}}$ is the expected electron-transfer rate constant for an aromatic anion radical with the same redox potential as the nucleophile. If $k_{\text {SUB }}$ $=k_{\mathrm{SET}}$ and the $\lambda$ values are equal, then $\Delta \Delta G^{*}=$ 0 and the two energy profiles in Fig. 3 will be identical. In this case the nucleophilic reaction can be classified as an outer-sphere SET reaction. If $k_{\mathrm{SUB}} / k_{\mathrm{SET}}$ is very high $\left(>10^{14}, \Delta \Delta G^{\neq}>20 \mathrm{kcal}\right.$ $\mathrm{mol}^{-1}$ ) then the TS can be characterized as a pure $\mathrm{S}_{\mathrm{N}} 2 \mathrm{TS}$.

For a given RX compound the rate constant, $k_{\mathrm{SET}}$, for electron transfer from a number of aromatic anion radicals with different redox potentials is obtained by cyclic voltammetry. ${ }^{26}$

The expected rate of electron transfer, $k_{\mathrm{SET}}$, for the reaction of RX with a nucleophile with the redox potential $E_{\mathrm{Nu}}$ can be obtained from the $\left(E_{\mathrm{A}}, \log k_{\mathrm{SET}}\right)$ curve (Fig. 4).

The kinetic results are shown in Tables 1,2 and 3. Rates of electron transfer from a series of aromatic anion radicals to benzyl bromide and 2-bromo-2-phenylbutane are shown in Table 4.

The reaction scheme for $1^{-}, \mathbf{1}^{-}$and $2^{-}$with alkyl $^{26}$ and benzyl halides ${ }^{27}$ is shown in eqns. (5)(7):

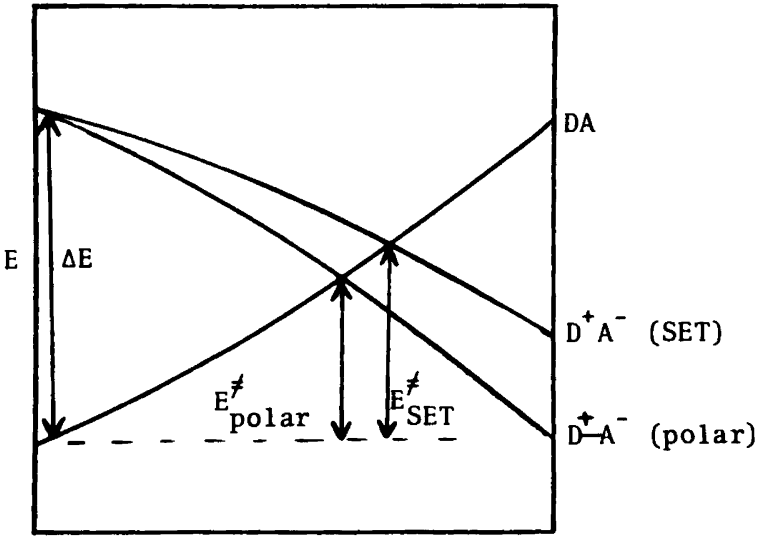

REACTION COORDINATE
Fig. 3. Schematic diagram illustrating the energy profiles for the SET and the polar pathways. $\Delta E^{\neq}$for the polar process is lower than for the SET process (from Ref. 22). 


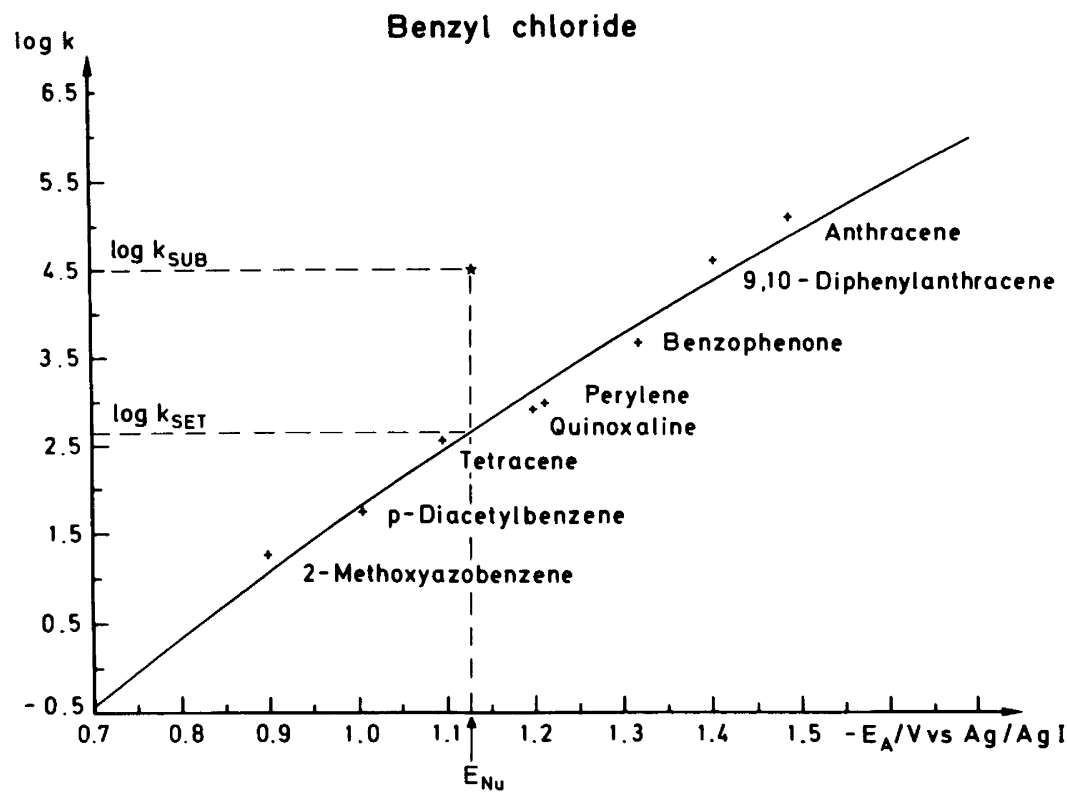

Fig. 4. Rate constants for electron transfer, $k_{\mathrm{SET}}$, from some electrochemically generated anion radicals $(+)$ to benzyl chloride, and rate constant for reaction between $1^{-}\left(^{\star}\right)$ and benzyl chloride in DMF/TBABF ${ }_{4}(0.1 \mathrm{M})$ (from Ref. 27).

$1^{+}+\mathrm{e}^{-} \rightleftharpoons 1^{-}$

$1^{\cdot}+\mathrm{e}^{-} \rightleftharpoons 1^{-}$

$1^{-}+R X \rightarrow\left[\cdot 1+\cdot R+X^{-}\right] \rightarrow 1-R+X^{-}$

Dianions react via the scheme of eqns. (8)-(10):

$A+e^{-} \rightleftharpoons A^{--}$

$\mathrm{A}^{--}+\mathrm{e}^{-} \rightleftharpoons \mathrm{A}^{2-}$

$\mathrm{A}^{2-}+\mathrm{RX} \rightarrow \mathrm{A}^{--}+\mathrm{R}^{-} \mathrm{X}^{-} \rightarrow \mathrm{A}-\mathrm{R}^{-}+\mathrm{X}^{-}$

BV and MV are generated in two steps from $\mathbf{B V}^{2+}$ and $\mathbf{M V}^{2+}$, respectively, and the reaction with benzyl bromide follows eqn. (11):

$\mathbf{B V}+\mathrm{RX} \rightarrow\left[\mathrm{BV}^{\bullet+}+\cdot \mathbf{R}+\mathbf{X}^{-}\right] \rightarrow \mathbf{B V}-\mathbf{R}^{-}+\mathrm{X}^{-}$

$\mathbf{B V}-\mathbf{R}^{+}$is the only product observed $(\mathrm{R}=$ benzyl).

19 Acta Chemica Scandinavica B 42 (1988)

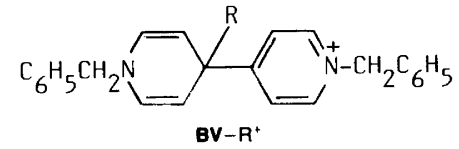

Discussion

In Table 1 a number of examples are shown where $k_{\mathrm{SUB}} / k_{\mathrm{SET}}=1$, suggesting that these reactions proceed through an outer-sphere SET mechanism. These examples are the reactions of $\mathbf{1}^{-}$with the sterically hindered alkyl halides adamantyl bromide, neopentyl bromide, $t$ - $\mathrm{BuBr}$, and 2-chloro-2-phenylbutane, and the reaction of $\mathbf{P e}^{2-}$ with $t$-BuCl.

The vicinal dihalides $d, l-1,2$-dichloro-1,2-diphenylethane (3- $d l)$ and meso-1,2-dichloro-1,2diphenylethane $(3-m)$ are reduced by $1^{-}$following a purely catalytic mechanism and with $k_{\mathrm{SUB}} / k_{\mathrm{SET}} \simeq 1 .{ }^{28}$ (Here, $k_{\mathrm{SUB}}$ is the rate constant for the first electron transfer from $1^{-}$to the vicinal dihalides.) This shows indirectly that the selfexchange reorganization energy, $\lambda(0)$, of $1 \% 1^{-}$is equal to the average self-exchange energy for the 
Table 1. Rate constants, $k_{\mathrm{SUB}}$, for the reaction of different nucleophiles with some $\mathrm{RX}$ compounds compared to $k_{\mathrm{SET}}$.

\begin{tabular}{|c|c|c|c|c|c|}
\hline Nucleophile & $\mathrm{RX}$ & $E_{\mathrm{Nu}}$ & $k_{\text {SUB }} / M^{-1} \mathrm{~s}^{-1}$ & $k_{\mathrm{SET}} / \mathrm{M}^{-1} \mathrm{~s}^{-1}$ & $k_{\mathrm{SUB}} / k_{\mathrm{SET}}$ \\
\hline $1^{-}$ & 1-Adamantyl bromide & -1.13 & $1.5 \times 10^{-2}$ & $1.9 \times 10^{-2}$ & 0.8 \\
\hline - & Neopentyl bromide & - & $2.9 \times 10^{-2}$ & $2.3 \times 10^{-2}$ & 1.3 \\
\hline- & $t-\mathrm{BuBr}$ & - & 30 & 12 & 2.5 \\
\hline- & $s-\mathrm{BuBr}$ & - & 480 & 2.8 & 170 \\
\hline- & $n-\mathrm{BuBr}$ & - & 1420 & 3.5 & 400 \\
\hline- & $\mathrm{CH}_{3} \mathrm{CH}_{2} \mathrm{Br}$ & - & 3052 & 1.2 & 2500 \\
\hline- & $\mathrm{PhC}\left(\mathrm{CH}_{3}\right)\left(\mathrm{CH}_{2} \mathrm{CH}_{3}\right) \mathrm{Cl}$ & - & 218 & 171 & 1.3 \\
\hline - & $\mathrm{PhCH}\left(\mathrm{CH}_{3}\right) \mathrm{Cl}$ & - & 2980 & 367 & 8.2 \\
\hline- & $\mathrm{PhCH}_{2} \mathrm{Cl}$ & - & $3.1 \times 10^{4}$ & 469 & 66 \\
\hline- & $d, I-\mathrm{PhCHCl}-\mathrm{CHCIPh}$ & - & 376 & 693 & 0.55 \\
\hline- & meso-PhCHCl-CHCIPh & - & 948 & 1745 & 0.54 \\
\hline $1^{\prime-}$ & $t-\mathrm{BuBr}$ & -0.886 & 23 & 0.08 & 290 \\
\hline- & sec- $\mathrm{BuBr}$ & - & 84 & 0.02 & 4200 \\
\hline- & $n-\mathrm{BuBr}$ & - & 141 & 0.07 & 2000 \\
\hline- & $\mathrm{PhC}\left(\mathrm{CH}_{3}\right)\left(\mathrm{CH}_{2} \mathrm{CH}_{3}\right) \mathrm{Cl}$ & - & 21 & 3 & 7 \\
\hline- & $\mathrm{PhCH}\left(\mathrm{CH}_{3}\right) \mathrm{Cl}$ & - & 107 & 3.4 & 33 \\
\hline- & $\mathrm{PhCH}_{2} \mathrm{Cl}$ & - & 540 & 6 & 90 \\
\hline- & $\mathrm{PhCH}\left(\mathrm{CH}_{3}\right) \mathrm{Br}$ & - & $1.6 \times 10^{5}$ & $4.5 \times 10^{3}$ & 36 \\
\hline - & $\mathrm{PhCH}_{2} \mathrm{Br}$ & - & $1.2 \times 10^{6}$ & $4 \times 10^{3}$ & 300 \\
\hline $\mathbf{2}^{-}$ & $\mathrm{PhCH}\left(\mathrm{CH}_{3}\right) \mathrm{Br}$ & -0.721 & $1.2 \times 10^{4}$ & 891 & 14 \\
\hline- & $\mathrm{PhCH}_{2} \mathrm{Br}$ & - & $59 \times 10^{3}$ & 562 & 105 \\
\hline- & $\mathrm{PhCH}\left(\mathrm{CH}_{3}\right) \mathrm{Cl}$ & - & 19.5 & 0.26 & 76 \\
\hline- & $\mathrm{PhCH}_{2} \mathrm{Cl}$ & - & 113 & 0.55 & 205 \\
\hline MV & $\mathrm{PhCH}\left(\mathrm{CH}_{3}\right) \mathrm{Br}$ & -0.350 & 54 & $4.5(18)^{a}$ & $12(3)$ \\
\hline- & $\mathrm{PhCH}_{2} \mathrm{Br}$ & - & 35 & $1.6(6.3)$ & $22(6)$ \\
\hline BV & $\mathrm{PhCH}\left(\mathrm{CH}_{3}\right) \mathrm{Br}$ & -0.287 & 137 & $1.6(6.3)$ & $86(14)$ \\
\hline- & $\mathrm{PhCH}_{2} \mathrm{Br}$ & - & 35 & $0.8(3.2)$ & $44(10)$ \\
\hline $\mathbf{P e}^{2-}$ & $t-\mathrm{BuCl}$ & -1.80 & 171 & 141 & 1.21 \\
\hline- & $s-\mathrm{BuBr}$ & -1.80 & $9.5 \times 10^{5}$ & $2.11 \times 10^{5}$ & 4.5 \\
\hline $\mathbf{A} \mathbf{Q}^{2-}$ & $s-\mathrm{BuBr}$ & -1.123 & 909 & 2.8 & 322 \\
\hline
\end{tabular}

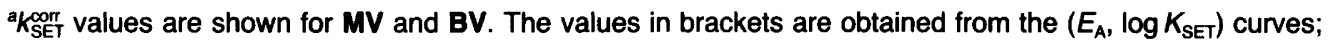
$k_{\mathrm{SET}}^{\mathrm{Corr}} \times 1 / 4 \times k_{\mathrm{SET}}$. See the text.

anion radicals $\left\langle\lambda_{A}(0)>10 \mathrm{kcal} \mathrm{mol}^{-1}\right.$. Recently, a value of $\lambda(0)=16.5 \mathrm{kcal} \mathrm{mol}^{-1}$ for the methylviologen system MV/MV ${ }^{++}$was obtained by ESR measurements..$^{29}$ The effect of the slightly higher $\lambda(0)$ value for the viologen nucleophiles $\mathbf{M V}$ and BV compared to the average $\lambda(0)$ value for the anion radicals $\left[\lambda \Delta(0)=\lambda_{\mathrm{MV}}(0)-<\lambda_{\mathrm{A}}(0)>=6.5\right.$ $\left.\mathrm{kcal} \mathrm{mol}^{-1}\right]$ is that the expected SET rates constants,

$k_{\mathrm{SET}}^{\text {corr }}$, for the viologen nucleophiles are somewhat smaller than $k_{\mathrm{SET}}$ obtained from the anion radical data. The increase in the expected SET free energy of activation, $\Delta \Delta G^{*}$, can be shown from eqns. 18 and 19 in Ref. 26 to be approximately equal to $\Delta \lambda(0) / 8=0.8 \mathrm{kcal} \mathrm{mol}^{-1}$, decreasing the expected SET rate by a factor of $4: k_{\mathrm{SET}}^{\text {corr }}=1 / 4$ $k_{\mathrm{SET}}$. If future measurements of $\lambda(0)$ values for the nucleophiles or anion radicals turn out to give values slightly different from $10 \mathrm{kcal} \mathrm{mol}^{-1}$, this will lead to a small correction of the tabulated values of $k_{\mathrm{SET}}$ and $k_{\mathrm{SUB}} / k_{\mathrm{SET}}$.

Dihydrobenzylviologen (BV) reacts with ben-

Scheme 3.
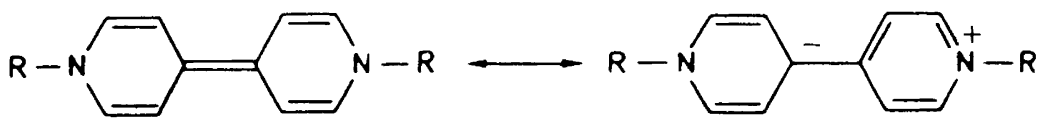
Table 2. Comparison of $k_{\mathrm{SUB}}$ and $k_{\mathrm{SUB}} / k_{\mathrm{SET}}$ for reactions of a given $\mathrm{RX}$ with different $\mathrm{Nu}$.

\begin{tabular}{|c|c|c|c|c|}
\hline $\mathrm{Nu}$ & $\mathrm{RX}$ & $E_{\mathrm{Nu}}$ & $k_{\mathrm{SuB}} / \mathrm{M}^{-1} \mathrm{~s}^{-1}$ & $k_{\mathrm{SUB}} / k_{\mathrm{SET}}$ \\
\hline $\begin{array}{l}1^{-} \\
1^{\prime-} \\
1^{-} \\
1^{\prime-} \\
1^{-} \\
1^{\prime-}\end{array}$ & $\begin{array}{l}t \text {-BuBr } \\
- \\
s-\mathrm{BuBr} \\
- \\
n-\mathrm{BuBr} \\
-\end{array}$ & $\begin{array}{l}-1.13 \\
-0.886 \\
-1.13 \\
-0.886 \\
-1.13 \\
-0.886\end{array}$ & $\begin{array}{l}30 \\
23 \\
480 \\
84 \\
1420 \\
141\end{array}$ & $\begin{array}{l}2.5 \\
290 \\
170 \\
4200 \\
400 \\
2000\end{array}$ \\
\hline $\begin{array}{l}1^{-} \\
1^{\prime-} \\
2^{-}\end{array}$ & $\begin{array}{l}\mathrm{PhC}\left(\mathrm{CH}_{3}\right)\left(\mathrm{CH}_{2} \mathrm{CH}_{3}\right) \mathrm{Cl} \\
= \\
-\end{array}$ & $\begin{array}{l}-1.13 \\
-0.886 \\
-0.721\end{array}$ & $\begin{array}{l}218 \\
21 \\
3.7\end{array}$ & $\begin{array}{l}1.3 \\
7 \\
17\end{array}$ \\
\hline $\begin{array}{l}\mathbf{1}^{-} \\
\mathbf{1}^{\prime-} \\
\mathbf{2}^{\prime-}\end{array}$ & $\begin{array}{l}\mathrm{PhCH}\left(\mathrm{CH}_{3}\right) \mathrm{Cl} \\
- \\
-\end{array}$ & $\begin{array}{l}-1.13 \\
-0.886 \\
-0.721\end{array}$ & $\begin{array}{l}2980 \\
107 \\
19.5\end{array}$ & $\begin{array}{l}8.2 \\
33 \\
76\end{array}$ \\
\hline $\begin{array}{l}1^{-} \\
1^{\prime-} \\
2^{-}\end{array}$ & $\begin{array}{l}\mathrm{PhCH}_{2} \mathrm{Cl} \\
- \\
-\end{array}$ & $\begin{array}{l}-1.13 \\
-0.886 \\
-0.721\end{array}$ & $\begin{array}{l}3.1 \times 10^{4} \\
540 \\
113\end{array}$ & $\begin{array}{l}66 \\
90 \\
205\end{array}$ \\
\hline $\begin{array}{l}\mathrm{Pe}^{2-} \\
\mathbf{1}^{-} \\
\mathrm{AQ}^{2-} \\
\mathbf{1}^{\prime-}\end{array}$ & $\begin{array}{l}s-\mathrm{BuBr} \\
- \\
- \\
-\end{array}$ & $\begin{array}{l}-1.80 \\
-1.13 \\
-1.123 \\
-0.886\end{array}$ & $\begin{array}{l}9.5 \times 10^{5} \\
480 \\
909 \\
84\end{array}$ & $\begin{array}{l}4.5 \\
170 \\
322 \\
4200\end{array}$ \\
\hline $\begin{array}{l}1^{-} \\
2^{-} \\
\text {MV } \\
\text { BV }\end{array}$ & $\begin{array}{l}\mathrm{PhCH}\left(\mathrm{CH}_{3}\right) \mathrm{Br} \\
- \\
- \\
-\end{array}$ & $\begin{array}{l}-0.886 \\
-0.721 \\
-0.35 \\
-0.287\end{array}$ & $\begin{array}{l}1.6 \times 10^{5} \\
1.2 \times 10^{4} \\
54 \\
135\end{array}$ & $\begin{array}{l}36 \\
14 \\
12 \\
56\end{array}$ \\
\hline $\begin{array}{l}1^{-} \\
2^{-} \\
\text {MV } \\
\text { BV }\end{array}$ & $\begin{array}{l}\mathrm{PhCH}_{2} \mathrm{Br} \\
- \\
- \\
-\end{array}$ & $\begin{array}{l}-0.886 \\
-0.721 \\
-0.35 \\
-0.287\end{array}$ & $\begin{array}{l}1.2 \times 10^{6} \\
5.9 \times 10^{4} \\
35 \\
35\end{array}$ & $\begin{array}{l}300 \\
105 \\
24 \\
40\end{array}$ \\
\hline
\end{tabular}

zyl bromide with coupling at $\mathrm{C}-4$ rather than at nitrogen to give $\mathbf{B V}-\mathbf{R}^{+}$. BV may be represented by the resonance forms shown in Scheme 3. A polar reaction would be expected to favour sub- stitution at nitrogen, although C-4 cannot be excluded as point of attack; however, a simple Hückel calculation performed on the viologen cation radical $\left(\mathrm{H}-\mathrm{V}^{\cdot+}\right)$ indicates the highest spin

Table 3. Comparison of $k_{\mathrm{SUB}}$ and $k_{\mathrm{SUB}} / k_{\mathrm{SET}}$ for reactions of a given Nu with different RX.

\begin{tabular}{llllll}
\hline $\mathrm{Nu}$ & $E_{\mathrm{Nu}} N$ & $\mathrm{R}$ & $\mathrm{X}$ & $k_{\mathrm{SUB}} / \mathrm{M}^{-1} \mathrm{~s}^{-1}$ & $k_{\mathrm{SUB}} / k_{\mathrm{SET}}$ \\
\hline $\mathbf{1}^{\prime-}$ & -0.886 & $\mathrm{PhCH}_{2} \mathrm{X}$ & $\mathrm{Cl}$ & 540 & 90 \\
$\mathbf{1}^{\prime-}$ & -0.886 & - & $\mathrm{Br}$ & $1.2 \times 10^{6}$ & 300 \\
$\mathbf{2}^{-}$ & -0.721 & - & $\mathrm{Cl}$ & 113 & 205 \\
$\mathbf{2}^{-}$ & -0.721 & - & $\mathrm{Br}$ & $5.9 \times 10^{4}$ & 105 \\
$\mathbf{1}^{\prime-}$ & -0.886 & $\mathrm{PhCH}\left(\mathrm{CH}_{3}\right) \mathrm{X}$ & $\mathrm{Cl}$ & 107 & 33 \\
$\mathbf{1}^{-}$ & -0.886 & - & $\mathrm{Br}$ & $1.6 \times 10^{5}$ & 36 \\
$\mathbf{2}^{-}$ & -0.721 & - & $\mathrm{Cl}$ & 19.5 & 76 \\
$\mathbf{2}^{-}$ & -0.721 & - & $\mathrm{Br}$ & $1.2 \times 10^{4}$ & 14 \\
\hline
\end{tabular}


Table 4. Rate constants $\left(k_{\mathrm{SET}}\right)$ and free enegies of activation for electron transfer from electrochemically generated anion radicals $(A)$ to some benzyl bromides $(R X)$ in DMF/0.1 M TBABF ${ }_{4}$ measured by cyclic voltammetry.

\begin{tabular}{llcrrr}
\hline $\mathrm{RX}$ & $\mathrm{A}$ & $-E_{\mathrm{A}} N$ & $k_{\mathrm{SET}} / \mathrm{M}^{-1} \mathrm{~s}^{-1}$ & $\log k_{\mathrm{SET}}$ & $\Delta G^{*} \mathrm{kcal} \mathrm{mol}^{-1}$ \\
\hline $\mathrm{PhCH}_{2} \mathrm{Br}$ & Azobenzene & 0.879 & 4323 & 3.64 & 10.04 \\
- & p-Chloroazobenzene & 0.783 & 1845 & 3.27 & 19.54 \\
- & m-Chloroazobenzene & 0.735 & 1277 & 3.11 & 10.76 \\
- & 4-Methoxycarbonylazobenzene & 0.611 & 95 & 1.98 & 12.30 \\
- & 2,2'-Azopyridine & 0.532 & 103 & 2.01 & 12.26 \\
- & Anthraquinone & 0.400 & 11.4 & 1.06 & 13.56 \\
$\mathrm{PhCH}\left(\mathrm{CH}_{3}\right) \mathrm{Br}$ & Azobenzene & 0.879 & 5964 & 3.78 & 9.85 \\
- & p-Chloroazobenzene & 0.783 & 2193 & 3.34 & 10.45 \\
- & m-Chloroazobenzene & 0.735 & 856 & 2.93 & 11.00 \\
- & 4-Methoxycarbonylazobenzene & 0.611 & 245 & 2.39 & 11.75 \\
- & 2,2'-Azopyridine & 0.532 & 141 & 2.15 & 12.07 \\
\hline
\end{tabular}

density of $\mathbf{H}-\mathbf{V}^{++}$to be at $\mathrm{C}-4$, which suggests that the preferred radical-radical coupling for the viologen would occur at C-4 (the calculation was performed with the heteroparameters $\alpha_{N}=$ $\alpha_{C}+2.0$ and $\beta_{N}=\beta_{C C} C$ ).

Predictions $A$ and $B$ of the VBCM model. In Table 1 it is seen for the reactions of $1^{-}, 1^{\prime-}$ and $2^{-}$that $k_{\mathrm{SUB}} / k_{\mathrm{SET}}$ decreases (the TS becomes more SET-like) when the steric hindrance of the substrate increases. This is in agreement with prediction A. An illustrative example is the reaction of $\mathbf{1}^{-}$with the series of alkyl halides from adamantyl bromide to ethyl bromide, where $k_{\text {SUB }} / k_{\text {SET }}$ increases from 1 to 2500 , equivalent to a bond energy in the TS of from 0 to $5 \mathrm{kcal} \mathrm{mol}^{-1}$. This may be taken as support for the model in which the mechanism changes continuously through the series from a pure SET to a mechanism with some $S_{\mathrm{N}} 2$ character. However, all the reactions are located in the SET end of the
$\mathrm{S}_{\mathrm{N}}$ /SET spectrum, since a bond energy equal to $0-5 \mathrm{kcal} \mathrm{mol}^{-1}$ in the TS is relatively small compared to the bond energy in the classical $\mathrm{S}_{\mathrm{N}} 2 \mathrm{TS}$ in which the interaction energy $\beta$ is approximately half of the bond strength of the $\mathrm{Nu}-\mathrm{C}$ bond (see Fig. 5).

BV and MV react faster with 1-bromo-1phenylethane than with benzyl bromide (Table 1). This unexpected result can only partly be explained on the basis of the Shaik and Pross model by the fact that 1-bromo-1-phenylethane is a slightly better electron acceptor than benzyl bromide (see Table 4).

The Finkelstein reaction between $\mathrm{I}^{-}$and $n$ - $\mathrm{BuBr}$ is an example of a nucleophilic reaction in the $\mathrm{S}_{\mathrm{N}} 2$ end of the $\mathrm{SET} / \mathrm{S}_{\mathrm{N}} 2$ spectrum. ${ }^{30}$ In Table $5, k_{\mathrm{SET}}$ and $k_{\mathrm{SUB}} / k_{\mathrm{SET}}$ data for the Finkelstein reaction and the reaction of $1^{-}$with $n-\mathrm{BuBr}$ are compared. The interaction energy in the TS for the Finkelstein reaction is very high, suggesting that the TS is similar to the classical $S_{N} 2$ TS.

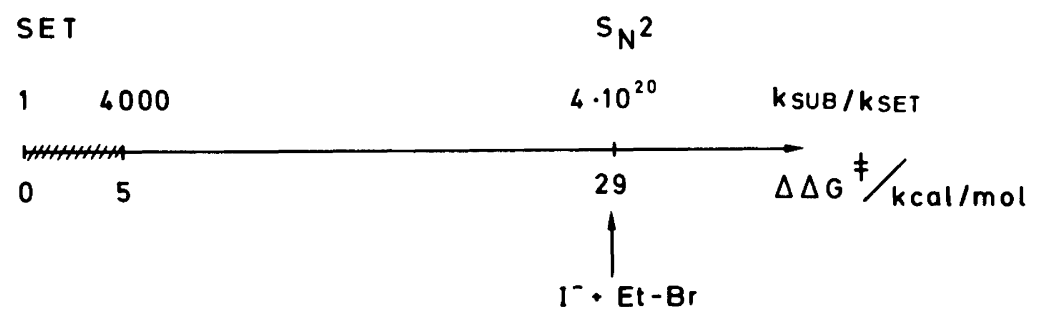

Fig. 5. SET/ $\mathrm{S}_{\mathrm{N}} 2$ diagram illustrating the continuous transition between a pure SET TS $\left(\Delta \Delta G^{*}=0\right)$ to a pure $\mathrm{S}_{\mathrm{N}} 2 \mathrm{TS}\left(\Delta \Delta G^{\neq}\right.$high). The reactions studied in this work fall on the hatched part of the SET/S 2 spectrum. 
Table 5. Comparison between $k_{\mathrm{SET}}$ and $k_{\mathrm{SUB}} / k_{\mathrm{SET}}$ values for the reactions of iodide and $1^{-}$with $\mathrm{EtBr}$.

\begin{tabular}{llc}
\hline & 1 & $1^{-}$ \\
\hline$E_{\mathrm{Nu}} / \mathrm{V}$ vs. NHE & $1.2^{a}$ & -1.48 \\
$k_{\mathrm{SET}} / \mathrm{M}^{-1} \mathrm{~s}^{-1}$ & $4 \times 10^{-24 b}$ & 1.2 \\
$k_{\mathrm{SUB}} / \mathrm{M}^{-1} \mathrm{~s}^{-1}$ & $1.7 \times 10^{-3 c}$ & $3052^{d}$ \\
$k_{\mathrm{SUB}} / k_{\mathrm{SET}}$ & $4 \times 10^{20}$ & 2500 \\
$\Delta \Delta G^{*} / \mathrm{kcal} \mathrm{mol}^{-1}$ & 29 & 4.8
\end{tabular}

${ }^{a}$ From Ref. 30. ${ }^{b}$ Calculated by the Marcus equation ${ }^{32}$ using the following data: $\lambda_{\mathrm{Et}-\mathrm{Br}}=116 \mathrm{kcal} \mathrm{mol}^{-1},{ }^{26}$ $E_{\mathrm{Et}-\mathrm{Br}}=-0.90 \mathrm{~V}$ vs. $\mathrm{NHE},{ }^{30} \lambda_{1 / n}-(0) \simeq 0 \mathrm{kcal} \mathrm{mol}^{-1}$. 'Measured in acetone. From Ref. 33. ${ }^{d}$ Measured in $\mathrm{N}, \mathrm{N}$-dimethylformamide.

Predictions $C$ and $D$ of the VBCM model. In Table 2 the results from Table 1 are arranged in series in which the nucleophiles are varied and RX is held constant. Except in the cases of the viologens $\mathrm{MV}$ and $\mathrm{BV}, k_{\mathrm{SUB}}$ increases when the electron-donating power of the nucleophile is increased $\left(E_{\mathrm{Nu}}\right.$ more negative). The redox potential of benzyl bromide has been calculated to be $0.2 \mathrm{~V}$ more positive than that for benzyl chloride, and benzyl bromide is thus a better electron acceptor than benzyl chloride..$^{30}$ From Table 1 it is seen that the bromides react 200-2000 times faster than the chlorides. The experimental results are thus in reasonably good agreement with prediction $\mathrm{C}$.

A linear correlation of half-wave potentials, $E_{1 / 2}$, with $\log k_{\text {obs }}$ has recently been demonstrated for a series of 9-substituted fluorenide anions reacting with 1,1-dinitrocyclohexane ${ }^{31}$ and 2-iodo-1,1,1-trifluoroethane. ${ }^{32}$ Similar correlations have been demonstrated previously. ${ }^{5}$

From prediction $\mathrm{D}$ we would expect a decrease in $k_{\mathrm{SUB}} / k_{\mathrm{SET}}$ when the electron-donating power of the nucleophile increases. This is seen to be the case of the examples shown in Table 2. An illustrative example in the series $\left(\mathrm{Pe}^{2-}, \mathbf{1}^{-}, \mathbf{A Q}^{2-}\right.$ and $1^{\prime-}$ in the reaction with sec-BuBr) where $k_{\mathrm{SUB}} / k_{\mathrm{SET}}$ changes from $4.5-4500$. However, the prediction is not fulfilled for the benzyl bromides. Furthermore, the simple model cannot account for the variation in $k_{\mathrm{SUB}} / k_{\mathrm{SET}}$ when comparing nucleophiles with large structural differences $\left(\mathbf{1}^{\prime-}, \mathbf{2}^{-}, \mathbf{M V}, \mathbf{B V}\right)$.

Is then the ratio $k_{\mathrm{SUB}} / k_{\mathrm{SET}}$ changed when the acceptor is changed from $\mathrm{RCl}$ to $\mathrm{RBr}$ and the nucleophile is held constant? In Fig. 6 the energy profiles are drawn schematically for both $\mathrm{RCl}$ and $\mathrm{RBr}$ using the following arguments: (a) The electron affinity $A_{\mathrm{RX}}$ for $\mathrm{RBr}$ is higher than that for $\mathrm{RCl}$. (b) the $\mathrm{C}-\mathrm{Br}$ bond energy, $D_{\mathrm{CX}}$, is smaller than the corresponding $D_{\mathrm{CX}}$ for $\mathrm{C}-\mathrm{Cl}$. The slope of the DA energy profile for $\mathrm{RBr}$ will therefore be expected to be smaller than the slope for the RCl DA profile. A decrease in $A_{\mathrm{RX}}$ results in a TS located earlier on the reaction coordinate $\left(k_{\mathrm{SUB}} / k_{\mathrm{SET}} \rightarrow 1\right)$. However, a decrease in $D_{\mathrm{CX}}$ results in the opposite effect (late TS, $k_{\mathrm{SUB}} / k_{\mathrm{SET}}$ increasing). In Fig. 6 the reaction of two nucleophiles $\mathrm{Nu}$ and $\mathrm{Nu}^{1}$ with $\mathrm{RCl}$ and $\mathrm{RBr}$ is depicted schematically. Fig. 6 illustrates that in case a which has the larger difference $I_{\mathrm{N}}-A_{\mathrm{RX}}$ the TS for $\mathrm{RBr}$ comes later on the reaction coordinate than that for $\mathrm{RCl}$, whereas the opposite is found in case $\mathrm{b}$ for nucleophile $\mathrm{Nu}^{1}$. From this simple model we would therefore expect that $k_{\mathrm{SUB}} / k_{\mathrm{SET}}$ in some cases will increase and in other cases decrease, depending on the nature of the nucleophile, when the acceptor is changed from $\mathrm{RCl}$ to $\mathrm{RBr}$.

In Table $3, k_{\mathrm{SUB}} / k_{\mathrm{SET}}$ data are arranged in series

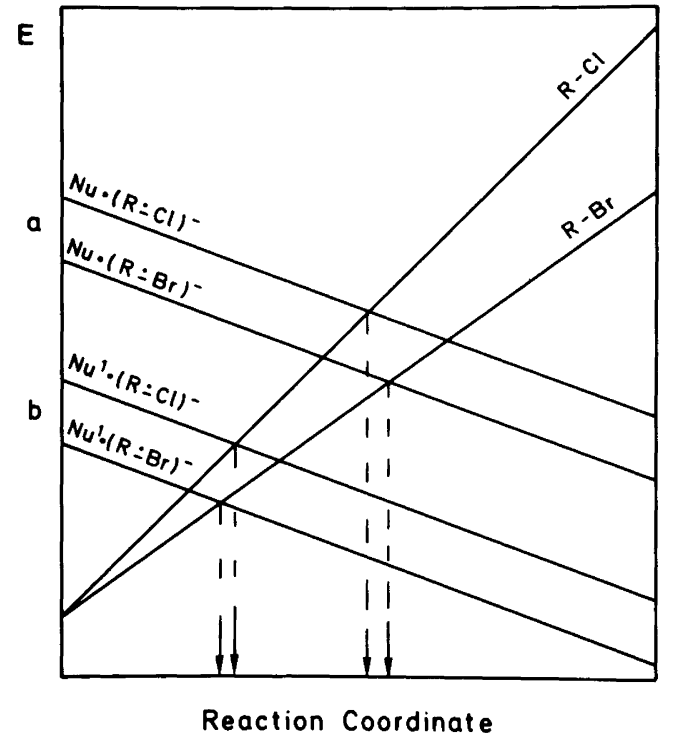

Fig. 6. Schematic energy diagram illustrating the effect of changing the acceptor from $\mathrm{R}-\mathrm{Cl}$ to $\mathrm{R}-\mathrm{Br}$ in two cases $(a$ and $b)$. The ionization potential of $\mathrm{Nu}, I_{\mathrm{Nu}}$, is higher than $/_{\mathrm{Nu}^{1}}$. The relative position of $\mathrm{TS}(\mathrm{RBr})$ and $\mathrm{TS}^{\prime}(\mathrm{RCl})$ is changed from $a$ to $b$. 
with nucleophiles held constant and the acceptor changing from $\mathrm{RCl}$ to $\mathrm{RBr}$. From Table 3 it is seen that all three possible situations are observed, i.e. $k_{\mathrm{SUB}} / k_{\mathrm{SET}}$ increases, decreases and remains unchanged when the acceptor is changed, in agreement with the simple energy profile considerations; thus the model is unable to predict the value of $k_{\mathrm{SUB}} / k_{\mathrm{SET}}$.

In the above discussion the experimental results have been analysed in the context of the Shaik and Pross model. However, it is also possible to discuss the kinetic results within the framework of the more classical and traditional view that the $\mathrm{S}_{\mathrm{N}} 2$ and SET mechanisms are two competing mechanisms where $k_{\text {SUB }}$ is the sum of two independent contributions in a manner similar to that discussed for aromatic electrophilic substitution: ${ }^{33,34}$

Further work, including the study of reactions with optically active alkyl halides, may throw light on whether the "continuous model" (Fig. 5) or the "competitive model" give the best predictions.

In summary, the predictions $A$ and $B$ are in accordance with the experimental results for the aliphatic nucleophilic substitution, the lowest $k_{\mathrm{SUB}} / k_{\mathrm{SET}}$ value being found for the sterically most hindered alkyl halides, while the higher $k_{\text {SUB }} / k_{\text {SET }}$ value for less hindered alkyl halides may be interpreted on the basis of weak bonding between $\mathrm{Nu}$ ' and ' $\mathrm{R}$ in the transition state, which would exemplify a TS between a pure SET TS and an $\mathrm{S}_{\mathrm{N}} 2 \mathrm{TS}$, and illustrate the "continuous TS" model.

The prediction $\mathrm{C}$ is fulfilled in many cases, but exceptions are found; whereas D works in some cases, it does not hold in nearly as many cases. It must thus be concluded that the VBCM model has reasonably good predictive power in the region of the "continuous TS" model which is SETlike, but even here other factors may overshadow the influence of the parameters involved in the VBCM model.

\section{Experimental}

Apparatus. The techniques and apparatus used have been described previously. ${ }^{26}$

Benzylviologen diperchlorate. $1.0 \mathrm{~g}$ of 4,4'-bipyridyl $-2 \mathrm{H}_{2} \mathrm{O}$ was dissolved in acetonitrile
$(5 \mathrm{ml})$, and benzyl bromide $(3 \mathrm{ml})$ was added. The mixture was heated in a stoppered flask to $80^{\circ} \mathrm{C}$ for $2 \mathrm{~h}$; the product began to precipitate during the reaction. The mixture was cooled, treated with diethyl ether, filtered and the product washed with diethyl ether; yield $2.6 \mathrm{~g}$ $(100 \%)$. The yellow product, 1,1'-dibenzyl4,4-bipyridinium dibromide, was purified by dissolving it in ethanol and precipitating the salt by addition of diethyl ether; m.p. $257-258^{\circ} \mathrm{C}\left(3^{\circ}\right.$ $\left.\min ^{-1}\right) .1 .0 \mathrm{~g}$ of the salt was dissolved in water $(15 \mathrm{ml})$, and sodium perchlorate $(1.0 \mathrm{~g})$ in water $(5 \mathrm{ml})$ was added. The precipitate was filtered off, washed with water and dried. The 1,1'-dibenzyl-4,4'-bipyridinium diperchlorate was recrystallized from acetonitrile; m.p. $\quad 270-272^{\circ} \mathrm{C}$ $\left(3^{\circ} \mathrm{min}^{-1}\right)$. ${ }^{1} \mathrm{H}$ NMR (DMSO- $\left.d_{6}\right): 5.9(4 \mathrm{H}, \mathrm{s})$, $7.4(10 \mathrm{~h}, \mathrm{~m}), 8.7\left(4 \mathrm{H}, \mathrm{d},{ }^{3} \mathrm{~J} 6 \mathrm{~Hz}\right), 9.5\left(4 \mathrm{H}, \mathrm{d},{ }^{3} J\right.$ $6 \mathrm{~Hz})$.

Reduction of benzylviologen and benzyl bromide. Benzylviologen $\left(\mathrm{BV}^{2+} \cdot 2 \mathrm{ClO}_{4}^{-}, 500 \mathrm{mg}, 0.93\right.$ $\mathrm{mM}$ ) was reduced at room temperature at a mercury pool electrode $(-0.4 \mathrm{~V}--0.5 \mathrm{~V}$ vs. $\mathrm{Ag} /$ AgI) in an acetonitrile solution containing $0.1 \mathrm{M}$ $\mathrm{LiClO}_{4}$. The acetonitrile was dried over molecular sieves ( $3 \AA$ ) prior to use. Nitrogen was bubbled slowly through the solution during the reduction. After completion of the reduction $\left(157 \mathrm{C}, 1.7 \mathrm{~F} \mathrm{~mol}^{-1}\right)$ benzyl bromide $(0.50 \mathrm{ml}$, $4.2 \mathrm{mM}$ ) was added, and after $1 / 2 \mathrm{~h}$ the yellow acetonitrile solution was evaporated and methylene chloride added. A precipitate of $\mathrm{LiClO}_{4}$ was removed by filtration. The volume of the filtrate was reduced, and after addition of diethyl ether a crystalline product $(510 \mathrm{mg})$ was obtained. The product was recrystallized from methylene chloride solution by addition of diethyl ether until the solution became slightly cloudy; the crystals were filtered off and $210 \mathrm{mg}$ of coupling product was obtained (yield $47 \%$ ). ${ }^{1} \mathrm{HNMR}$ (DMSO- $d_{6}$ ): d $3.00(2 \mathrm{H}, \mathrm{s}), 4.20(2 \mathrm{H}, \mathrm{s}), 4.58\left(2 \mathrm{H}, \mathrm{d},{ }^{3} \mathrm{~J}\right.$ $7.6 \mathrm{~Hz}), 5.78(2 \mathrm{H}, \mathrm{s}), 6.11\left(2 \mathrm{H}, \mathrm{d},{ }^{3} \mathrm{~J} 7.6 \mathrm{~Hz}\right)$, $6.5-7.5(15 \mathrm{H}, \mathrm{m}), 8.12\left(2 \mathrm{H}, \mathrm{d},{ }^{3} \mathrm{~J} 6.6 \mathrm{~Hz}\right), 9.05$ $\left(2 \mathrm{H}, \mathrm{d},{ }^{3} J 6.6 \mathrm{~Hz}\right)$.

Acknowledgement. We thank R. Fuhlendorff for the measurement of a number of rate constants used in this article. 


\section{References}

1. Ingold, C. K. Structure and Mechanism in Organic Chemistry, Cornell University Press, New York (1957).

2. March, J. Advanced Organic Chemistry, 3rd ed., Wiley, New York 1985.

3. Fleming, I. Frontier Orbitals and Organic Chemical Reactions, Wiley-Interscience, New York 1976.

4. Russell, G. A. and Lamson, D. W. J. Am. Chem. Soc. 91 (1969) 3967.

5. Bank, S. and Noyd, D. A. J. Am. Chem. Soc. 95 (1973) 8303.

6. Ashby, E. C., Bac, D. H., Park, W.S., Depriest, R. N. and Su, W. Y. Tetrahedron Lett. 25 (1984) 5107.

7. Ashby, E. C. and Pham, T. N. J. Org. Chem. 51 (1986) 3598.

8. Ashby, E. C., Park, W.S., Goel, A. B. and Su, W.-Y. J. Org. Chem. 50 (1985) 5184.

9. Ashby, E. C., Goel, A. B. and DePriest, R. N. J. Org. Chem. 46 (1981) 2429.

10. Ashby, E. C. and Goel, A. B. J. Am. Chem. Soc. 103 (1981) 4983.

11. Ashby, E. C. and Park, W. S. Tetrahedron Lett. 24 (1983) 1667.

12. Holm, T. Acta Chem. Scand., Ser. B 37 (1983) 567.

13. House, H. O. and Weeks, P. D. J. Am. Chem. Soc. 97 (1975) 2770.

14. Russell, G. A., Jawdosiuk, M. and Makosza, M. J. Am. Chem. Soc. 101 (1979) 2355.

15. Nugent, W. A., Bertini, F. and Kochi, J. K. J. Am. Chem. Soc. 96 (1974) 4945.
16. Kaim, W. Acc. Chem. Res. 18 (1985) 160.

17. Kochi, J. K. Acc. Chem. Res. 7 (1974) 351.

18. Perrin, C. L. J. Am. Chem. Soc. 99 (1977) 5516.

19. Burnett, J. F. Acc. Chem. Res. 11 (1978) 413.

20. Kornblum, N. Angew. Chem. 87 (1975) 797.

21. Pross, A. and Shaik, S. S. Acc. Chem. Res. 16 (1983) 363.

22. Pross, A. Acc. Chem. Res. 18 (1985) 212.

23. Shaik, S. S. Prog. Phys. Org. Chem. 15 (1985) 197.

24. Pross, A. Adv. Phys. Org. Chem. 21 (1985) 99.

25. Shaik, S. S. J. Am. Chem. Soc. 103 (1981) 3692.

26. Lund, T. and Lund, H. Acta Chem. Scand., Ser. B 40 (1986) 470.

27. Lund, T. and Lund, H. Acta Chem. Scand., Ser. B 41 (1987) 93.

28. Lund, T., Pedersen, S. U., Lund, H., Cheung, K. M. and Utley, J. H. P. Acta Chem. Scand., Ser. B 41 (1987) 285.

29. Fuhlendorff, R., Lund, T., Lund, H. and Pedersen, J. A. Tetrahedron Lett. 28 (1987) 5335.

30. Eberson, L. Acta Chem. Scand., Ser. B36 (1982) 533.

31. Bordwell, F. G. and Bausch, M. J. J. Am. Chem. Soc. 108 (1986) 1985.

32. Bordwell, F. G. and Wilson, C. A. J. Am. Chem. Soc. 109 (1987) 5470.

33. Lau, W. and Kochi, J. K. J. Am. Chem. Soc. 108 (1986) 6720.

34. Lau, W. and Kochi, J. K. J. Am. Chem. Soc. 106 (1984) 7100 .

Received October 5, 1987. 